\title{
Development of Protective Industrial Mask for Working in Clensol Environment
}

\author{
Vignesh Sreekandan Nair*, Jothiraj Palaniappan, Vasanth Prasad, Winowlin Jappes J T
}

\begin{abstract}
The proper mixing of the fuel and the air before the entry of engine makes the automobile vehicles to function properly. This accurate mixing can be obtained with the solitude great performance of carburetors. The performance of the carburetors is being checked continuously with sequential development during manufacturing processes. Once the development of the carburetor with the coverings is completed, their performances are in need to be checked. As the fuel used possess characteristics such as high reactivity with atmospheric oxygen, lesser density and high volatility, it cannot be used in the testing process. Hence fuel with the equivalent chemical formula as that of petrol is to be chosen and was found to be clensol. Owing to the above reasons, it is used to test the performance of carburetor especially for inspecting the movement of float and to detect leakage and so on. Hence they are used to test the performance of the carburetor as movement of float, leakage etc. Though this chemical seems to be a gift for the industry, it seems to have a lot of disadvantages because of this highly volatility which greatly placed the major role in decrementing the respiratory health of human work force leading to the throat infection, lung infection and often results in dermatological issues. Despite protective mask which are being provided by the industries to the work in order to avoid direct inhalation of volatile clensol. The detrimental effects were found not to be reduced up to the mark. Hence, this project deals with the development of mask with the suitable materials which will reduce the amount of clensol penetration in the inhaling air. The

reduction of clensol level in the developed mask was tested and tabulated.
\end{abstract}

Keywords : Carburretors, Clensol, Protective mask, Safety.

\section{INTRODUCTION}

$T_{\text {he protection from the various dust, infectious aerosols }}$ and the allergens are usually obtained from the usage of the protective masks in the industrial premises. There are enormous varieties of materials used for the fabrication of the mask. But all the developed materials are not even up to the safety limit. The study was done in the Southern Research

Revised Manuscript Received on December 15, 2019.

* Correspondence Author

Vignesh Sreekandan Nair*, Department of Mechanical Engineering, Kalasalingam, Academy of Research and Education, Krishnankoil, India, vignesh@klu.ac.in

Jothiraj Palaniappan, Department of Mechanical Engineering, Kalasalingam, Academy of Research and Education, Krishnankoil, India, jothiraj@klu.ac.in

Vasanth Prasad, Department of Mechanical Engineering, Kalasalingam, Academy of Research and Education, Krishnankoil, India,vasanthp@gmail.com

Winowlin Jappes JT, Department of Mechanical Engineering, Kalasalingam, Academy of Research and Education, Krishnankoil, India, winowlin@klu.ac.in
Institute, Birmingham, Alabama by the researcher Larry E. Bowen [1], where his results show that the usage of different types of face masks may not provide much protection as desired against inhaled aerosols. But usually there might the necessity for the mask as there might the age of $23 \%$ women and the average age was 47 as mentioned in the result huge amount of waste released from the petrochemical employees on the installations in the companies have been of research relatively stable over the last years where the installations had $76 \%$ men and industry. The major distribution of the gender and mean work done by Linn Iren vesley Berg[2]. He also shown that, psychosocial risk indicators useful in the effort of preventing the risk for HC leaks, could be used as one of several sources of information for monitoring the risk for $\mathrm{HC}$ leaks and one of several pragmatic criteria for determining where to implement preventive safety measures."When respiratory protection is in need for the exposures against bio-aerosols, the certified/approved particulate respirator should be selected by the users" according to the recommendations from CDC, WHO or applicable local agencies. As the various mechanism has been used in the particular filtration, it is not typically difficult to filter the smallest particle by them [3]. Though all the mask does not have same structural phenomena, majority of the particulate filters available in the market have a region of lower filtration efficiency which is somewhere between $0.05-0.5 \mu \mathrm{m}$.[4] and also explains that particles in this range are large enough to be less effectively pushed around by diffusion, but small enough to be less effectively captured by interception or impaction. The complete analysis of the petroleum leakage problem was done by the Terje Avena [5], where the research concludes that the workers in the petrochemical industry faces the problem when there arises the problem of leakage and their modification that was done in UK continental shelves. But the companies that involves the workers to have direct contact with the petrol for the testing, examining the performance must have the high level of safety. The study done by the Anne Mette Bjerkan[6] concludes that work done in group has to be taken into account, the effects of work safety climate and perception of the work environment on subjective health status as well as accident frequency. One investigation of respirators done by Eninger[7] started his research in incorporating antimicrobial-treated filter media and found that there was non-detectable or no effect on the viability of penetrating particles. There a study was done during the second world war to understand the performance of the protective mask with the variation in the concentrations and length of uncoated and coated fibres in the lungs of tested workers, where the gas-mask factories were measured after death with the light microscope using the membrane filter technique.[8]. Also, the technique name 
spun-bonding is merely a developing technology where the fabrics are produced by depositing extruded, spun filaments onto a collecting belt in a uniform random manner followed by bonding the fibers. This process involves the separation of fibers during the web laying process by air jets or electrostatic charges. The collecting surface is usually perforated to prevent the air stream from deflecting and carrying the fibers in an uncontrolled manner.[9]. With the analysis, the non-woven fiber is considered to be the biodegradable which is considering to be the highly using fiber in the masks. The property of non- woven fiber in the biodegradability was examined and was reported by Sunghyunnam in his research.[10].

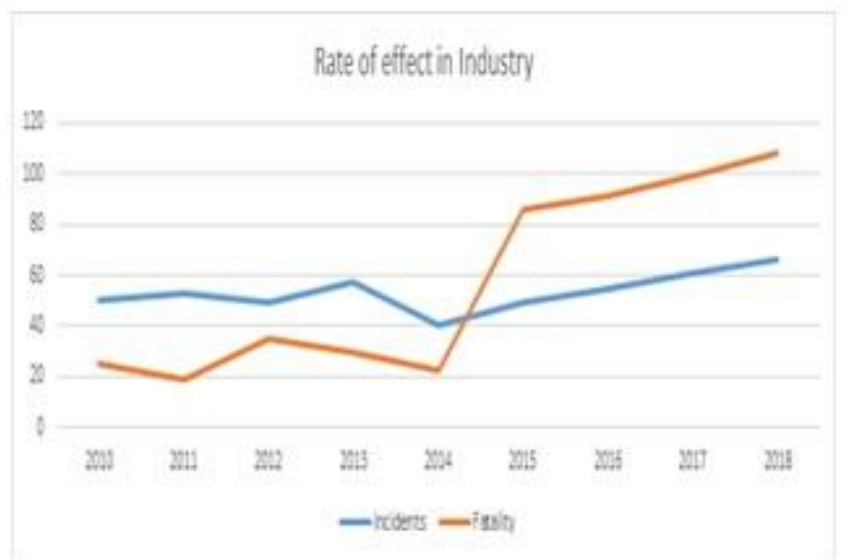

Fig.1. Rate of Effects in Industry

\section{FACTORS INFLUENCING THE USAGE OF WRONG MASK}

The topic of this study is analyzing the problem that the workers and the industrial people used to face when they came to use the wrong mask which is building on a broader tradition in high hazard industrial activities, especially from the petrochemical industry, chemicals involving factories and hence the efforts have been made to link factors that are related to human performance with safety results.

Due to the availability of the various kind of masks which are varying themselves with the geometry that it covers the area of the face, design, fabrication with the different materials and the way of producing them. As far as the analysis as done, the concept of using the mask was the traditional way of avoiding themselves from the dust, pollens in the working environment covered with huge amount of smoke.[11] Within the given oil and gas industry, the traditional way of achieving the safety has been changed to start their focus towards the technical factors, such as leakage sources (i.e. , flanges, valves and various other equipment), service periods, weight and overall technical condition of the platforms [12]

Majority of the Industries involving with the manufacturing of the automobile parts using the petrochemical mixtures are providing their workers the safety mask. As the function of the safety mask which is having the sieve diameter varies from the chemical mask will produce the adverse effect as that of the required mask. But, on the other hand, the industries involving the usage of the hazardous chemicals such as petrol should make their workers safe by providing the mask which should involve the mechanism of electrical charge dispersion and avoid the entrance of the gaseous particle in their breathing air.

\section{EXPERIMENTAL SETUP}

\section{Fibre Fabrication}

With the help of the spun bonding technology, which involves the various steps to obtain the fiber from the raw material which we have taken here is polypropylene. The material has been made to undergo the extrusion process where the bulk amount of polypropylene is made to extrude through the small opening in the form of thread. The hole takes up the size of the thread that is in need to add as a coat for the ordinary cotton mask. To extrude the polypropylene from the hole of diameter $10 \mathrm{~mm}$, it has been heated till it reaching its semi-molten condition which is name as hot extrusion process. The extruded material might be having some kind of raw- waste mingled with the useful material.

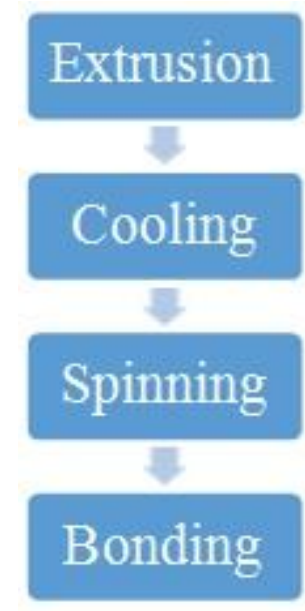

\section{Fig.3. Process Involved}

Hence, to use the same for the mask fabrication, it is in need to be cooled and cleaned. Hence, manual cleaning has been done and it was made to be air-cooled. The cooled material having complications, which is to be cleared and made into the desired fibre. So, the process of spinning which involves the twisting together of drawn-out strands of fiber to form a kind of yarn. This process of spinning had been made with the connections from the previously cooled fibre in the form of two rotating wheels. Since, the spinned thread having the thickness more than that of the required thread, it is made to draw to reduce its thickness. The drawing process is done with the set-up to tighten the thread and in this manner, there arises the reduction in thickness and the elongation of the thread. The output of drawn material is made to pass through the bonding roller. Since, the spun-bonding is suggested for its way of bonding during the spinning process, this plays the major role in the formation of polypropylene coating. The rollers with the increased temperature ranges from 50 to $80^{\circ} \mathrm{C}$, has been made to roll over the material which was already arranged in an order to be formed. The spun-bonded polypropylene coating, which is

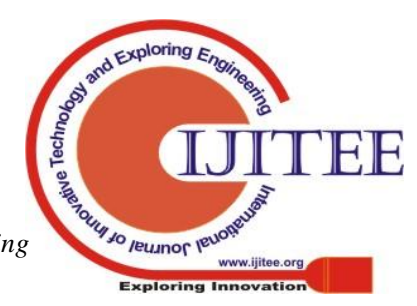


in hot condition, is made to roll over the cotton sheet fabricated in the shape of protective mask.

\section{Test Set-up}

The developed and fabricated spun-bonded polypropylene mask is now ready for the analysis of their performance. The simple experimental procedure to determine the efficiency of the mask has been done as shown in the Fig.3. .In the test set-up, under atmospheric pressure and temperature, $500 \mathrm{mg}$ of petrol has been measured and taken in the test apparatus (a rectangular glass with the opening in the top). Once it is filled in the apparatus, the top cover has been covered with the mask that has been spun bonded with polypropylene material. Hence, the amount of reduction in the quantity of petrol has been noted and the readings are tabulated. In order to have a stable record, it has been done in second time and the same has been noted.

Table-I: Weight calculation of SBPP mask

\begin{tabular}{|c|c|c|c|c|c|}
\hline $\begin{array}{c}\text { SI. } \\
\text { No }\end{array}$ & $\begin{array}{c}\text { Time } \\
\text { (hrs) }\end{array}$ & $\begin{array}{c}\text { Weight } \\
\text { measured- } \\
\text { 1 }\end{array}$ & $\begin{array}{c}\text { Weight } \\
\text { measured } \\
\mathbf{- 2}\end{array}$ & $\begin{array}{c}\text { Average } \\
\text { weight }\end{array}$ & $\begin{array}{c}\text { Reduction } \\
\text { in wt }\end{array}$ \\
\hline 1 & 0 & 500 & 500 & 500 & 0 \\
\hline 2 & 1 & 478 & 475 & 476.5 & 23.5 \\
\hline 3 & 2 & 454 & 452 & 453 & 23.5 \\
\hline 4 & 3 & 428 & 425 & 426. & 26.5 \\
\hline 5 & 4 & 404 & 400 & 402 & 24.5 \\
\hline 6 & 5 & 379 & 379 & 379 & 25 \\
\hline 7 & 6 & 356 & 356 & 356 & 23 \\
\hline
\end{tabular}

To analyse the performance of the developed spun-bonded polypropylene mask, the same process of compressor in the vertical hole has been fitted up and the top hole has been covered with the previously used safety mask available in the industry. The readings with the same time duration has been noted and tabulated in table II.

Table-II: Weight calculation of Safety mask

\begin{tabular}{|c|c|c|c|c|c|}
\hline SI.No & $\begin{array}{c}\text { Time } \\
\text { (hrs) }\end{array}$ & $\begin{array}{c}\text { Weight } \\
\text { measured- } \\
\mathbf{1}\end{array}$ & $\begin{array}{c}\text { Weight } \\
\text { measured } \\
\mathbf{- 2}\end{array}$ & $\begin{array}{c}\text { Average } \\
\text { weight }\end{array}$ & $\begin{array}{c}\text { Reduction } \\
\text { in wt\% }\end{array}$ \\
\hline 1. & 0 & 500 & 500 & 500 & 0 \\
\hline 2. & 1 & 455 & 457 & 456 & 44 \\
\hline 3. & 2 & 412 & 415 & 413.5 & 42.5 \\
\hline 4. & 3 & 370 & 372 & 371 & 42.5 \\
\hline 5. & 4 & 326 & 329 & 327.5 & 43.5 \\
\hline 6. & 5 & 280 & 284 & 282 & 45.5 \\
\hline 7. & 6 & 230 & 239 & 239 & 43 \\
\hline
\end{tabular}

Since, the gasoline evaporates in the faster mean which was $4.5 \mathrm{wt} \%$ to $5.3 \mathrm{wt} \%$ of the initial quantity of the gasoline within 2 hours of exposure to the open air at $70 \mathrm{~F}$ as mentioned by the researcher Ted R. Aulich, X-Inming He [13]. The second reading has been taken with the same quantity as that of first reading to avoid the mistake which might be happening with the human mistakes.

\section{RESULTS AND DISCUSSIONS}

After the data obtained from the rate of evaporation of petrol with the spun-bonded polypropylene mask and the regular safety mask has been plotted in the graph to understand their performance and shown in the Fig. 4 and Fig.5.
Also, from the data obtained, there exist the average reduction of weight percentage in the spun-bonded polypropylene mask is having its average over the 6 hours is $24.33 \mathrm{mg}$ which is $4.03 \%$ reduction in 1 hour time interval. On the other hand, there exist the average reduction of weight percentage in the regular safety mask is having its average over the 6 hours is $43.5 \mathrm{mg}$ which is $8.7 \%$ reduction in 1 hour. The performance analysis has been done to compare the amount of fuel that the mask has been protected from missing out of the testing apparatus is as shown in Fig.6

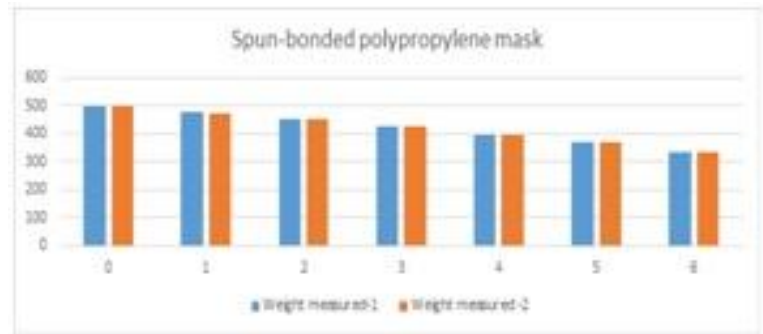

Fig.4. SBPP mask weight readings

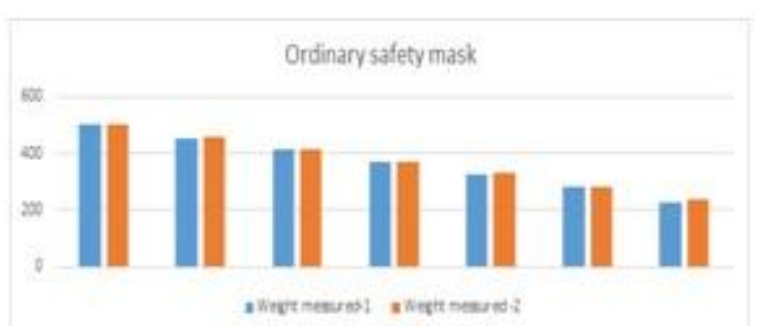

Fig.5. Ordinary mask weight readings

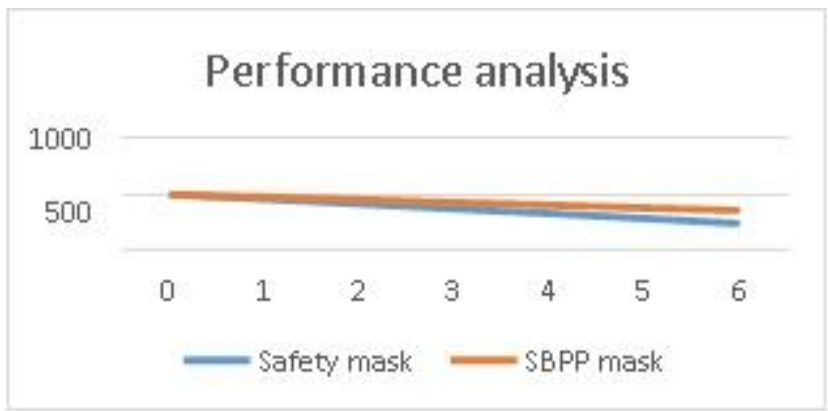

Fig.6. Performance Results

Mask comparison efficiency formula:

$(\mathrm{E} \%)=[(\mathrm{C}-\mathrm{Co}) / \mathrm{C}] \mathrm{X} 100$

$\mathrm{C}=$ Protective mask's wt reduction $\mathrm{Co}=\mathrm{SBPP}$ mask's wt reduction

Hence, by applying the above mentioned formula, the efficiency of the spun-bonded Polypropylene mask has been founded to be $53.67 \%$ more effective than the safety mask that is used in the industrial premises in the petrochemical environment.

\section{CONCLUSION}

Thus under the environmental condition of atmospheric room temperature, pressure, regularly used safety mask has been challenged with the spun-bonded polypropylene rolled over the cotton mask. 
The only parameter taken is to examine their performance of arresting the petrol from passing their medium. The spun bonded polypropylene mask has performed effectively when compared to the ordinary safety mask. This was mathematically verified as $54.67 \%$ effective functioning of the spun bonded polypropylene was observed over the ordinary safety mask. This efficiency of spun- bonded polypropylene over the safety mask was not considering the general disturbances such as smoke, pollens, dusts and other toxic substances.

\section{REFERENCES}

1. LarryE.Bowen Southern Research Institute, Birmingham, Alabama Does That Face Mask Really Protect You?

2. Linn Iren Vestly Bergh a,b,1, Arne Jarl Ringstad Gerard I.J.M. Zwetsloot. Psychosocial risks and hydrocarbon leaks: an exploration of their relationship in the Norwegian oil and gas industry.

3. Respiratory Protection for Airborne Exposures to Biohazards Technical data bulletin

4. New York: John Wiley \& Sons, 1999. Hinds, W.C.: Aerosol Technology: Properties, Behavior and Measurement of Airborne Particles.

5. TerjeAvena, 2011On risk assessment in the petroleum activities on the Norwegian and UK continental shelves

6. Anne MetteBjerkanHealth, environment, safety culture and climate analysing the relationships to occupational accidents

7. Aven and Pitblado, 1998; Vinnem et al., 2006, Barrier and operational risk analysis of hydrocarbon releases (BORA-Release): Part I. Method description

8. Eninger, R.M., Adhikari, A., Reponen, T., and S.A. Grinshpun. Differentiating Between Physical and Viable Penetrations.When Challenging Respirator Filters with Bioaerosols. Clean 36(7), 615-621; 2008.

9. A Morgan, A Holmes.Concentrations and characteristics of amphibole fibres in the lungs of workers exposed to crocidolite in the British gas-mask factories, and elsewhere, during the second world war.

10. AtulDahiya, M. G. Kamath, Raghavendra R. Hegde (Hsu-Yeh Huang and Xiao Gao), Spunbond Technology Updated,April, 2004

11. Comparison of biodegradation of low-weight hydroentangled raw cotton nonwoven fabric and that of commonly used disposable nonwoven fabrics in aerobic Captina silt loam soil

12. Weick and Sutcliffe, 2007, Psychosocial risks and hydrocarbon leaks: an exploration of their relationship in the Norwegian oil and gas industry Stanton et al., 2005.

13. Ted.Aulich, Xinming He, Ames A.Grisanti and Curtis L.Knudson.Gasoline Evaporation- Ethanol and nonethanol blends.

\section{AUTHORS PROFILE}

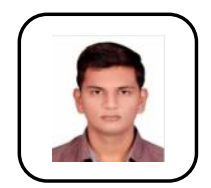

Vignesh Sreekandan Nair has graduated in the field of Mechanical Engineering from Anna University in 2013. He completed his post-graduation in Manufacturing Engineering from Anna University in 2016. He has published one paper in peer reviewed journal. His research area of interests are casting of non-ferrous alloys, development of polymer composites and mechanical behavior of materials. Presently he is working with Kalasalingam Academy of Research and Education as an Assistant professor in the department of Mechanical Engineering.

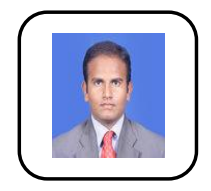

Jothiraj Palaniappanhas completed his bachelor's degree in the department of Mechanical Engineering under Anna University with First rank and gold medal, proceeded with the degree of masters under the Manufacturing Engineering with First Rank and Gold medal. He is being nominated and selected as the Mentor for change under the NITI-Ayog, Govt. of India for AIM. Has published two papers in peer reviewed journals. Active member in the IAEng. Research interest being inclined towards the advanced materials as shape memory alloys and phase changing materials

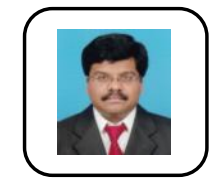

Winowlin Jappes J $\mathbf{T}$ graduated in 1997 from Manonmaniam Sunderanar University, India in Mechanical Engineering. In 1999, he has completed his masters in Production Engineering from Annamalai University. He completed his Ph.D degree in 2004 in the area of Composite Deposition at Indian Institute of Technology Madras, Chennai. He has completed three DST funded research projects and published more than 125 research articles which includes 65 International Journal papers. Currently, he is working as Senior Professor in Kalasalingam University, India. His research interests includes high performance composite materials, machining of hard materials, optimization techniques, etc. At present, he is working as Professor and Dean, School of Automotive and Mechanical Engineering, Kalasalingam Academy of Research and Education, India. 